\title{
pesquisa
}

SILVEIRA, E.B.; GOMES, A.M.A.; FERRAZ, E.; MARANHÃO, E.A.A.; MARIANO, R.L.R. Identificação de progênies de tomateiro resistentes à murcha-bacteriana. Horticultura Brasileira, Brasília, v. 17, n. 1, p. 06-10, março 1999.

\section{Identificação de progênies de tomateiro resistentes à murcha-bacteriana.}

\author{
Elineide B. Silveira1; Andréa M. A. Gomes²; Edinardo Ferraz ${ }^{3}$; Elizabeth A. A. Maranhão후 Rosa L. R. \\ Mariano $^{2}$ \\ ${ }^{1}$ IPA - Estação Experimental de Vitória de Santo Antão, C. Postal 0003, 55600-000, Vitória de Santo Antão - PE; E-mail: ebsilveira@yahoo.com; \\ ${ }^{2}$ UFRPE - DEPA, Área de Fitossanidade, 52171-900, Recife - PE; ${ }^{3}$ IPA - Estação Experimental de Belém do São Francisco, $56400-000$ - PE
}

\section{RESUMO}

Uma amostra de 660 plantas de uma população $\mathrm{F}_{6}$ de tomateiro, obtida pelo cruzamento das cultivares CL5915-93 (moderadamente resistente) e IPA-6 (suscetível) foi avaliada para resistência a Ralstonia solanacearum em condições de campo $\left(28 \pm 4^{\circ} \mathrm{C}\right.$ e UR 70 $\pm 5,5 \%$ ), em março de 1996 na UFRPE. Plantas com 20 dias foram inoculadas com a biovar III do patógeno pela deposição de $5 \mathrm{ml}$ de uma suspensão $\left(5 \times 10^{8} \mathrm{UFC} / \mathrm{ml}\right)$ na base de cada planta, duas horas antes do transplantio para canteiros no campo. As avaliações foram realizadas em intervalos semanais até os 70 dias após inoculação. No final do ciclo da cultura foram selecionadas 151 plantas que não apresentaram sintomas e desse material, uma progênie foi retrocruzada com a cultivar IPA-6. Em casa-de-vegetação, 40 progênies (geração $F_{2}$ ) resultantes deste retrocruzamento foram selecionadas para resistência, em setembro de $1997\left(35 \pm 5,5^{\circ} \mathrm{C}\right.$ e UR de $77 \pm 2,5 \%$ ). A metodologia de inoculação foi a mesma descrita anteriormente. As avaliações foram realizadas aos quatro, sete, dez, treze e 16 dias após a inoculação, estimando-se a incidência e severidade da doença. Foi também avaliado o comportamento de resistência das plantas através dos períodos de incubação e latência. Vinte e oito dias após a inoculação, avaliou-se ainda a existência de infecção latente nas progênies resistentes, pela presença de escurecimento dos vasos e isolamento do patógeno. Foi observada incidência da doença em $95 \%$ das progênies. Oito progênies foram classificadas como moderadamente resistentes e oito como resistentes. Os períodos médios de incubação e latência observados foram curtos (4,5 e 4,8 dias) para a testemunha suscetível e longos (11,6 e 12,9 dias), para as progênies resistentes. Foi detectada infecção latente em $45 \%$ das progênies resistentes.

Palavras-chave: Lycopersicon esculentum, Ralstonia solanacearum, Pseudomonas solanacearum, resistência genética, inoculação, condições controladas, incidencia, severidade, curva de progresso da doença, melhoramento.

\begin{abstract}
Identification of tomato progenies for resistance to bacterial wilt.

Six hundred and sixty $\mathrm{F}_{6}$ plants obtained from the crossing of cultivars CL5915-93 (moderately resistant) and IPA-6 (susceptible) were screened for resistance to bacterial wilt (Ralstonia solanacearum) under field conditions $\left(28 \pm 4^{\circ} \mathrm{C}\right.$ and $\left.\mathrm{RH} 70 \pm 5,5 \%\right)$ in March 1996 at UFRPE. Twenty-day-old seedlings were inoculated with biovar III of the pathogen by pouring $5 \mathrm{ml}$ of a suspension $\left(5 \times 10^{8} \mathrm{UFC} / \mathrm{ml}\right)$ at the base of each seedling, two hours prior to transplanting. Evaluations were performed at weekly intervals until 70 days after inoculation. At the end of the crop cycle, 151 symptomless plants were selected and from this material one progeny was backcrossed with the cultivar IPA-6. 40 progenies $\left(F_{2}\right)$ from this backcross were screened for resistance under greenhouse conditions $\left(35 \pm 5,5^{\circ} \mathrm{C}\right.$ and $\left.\mathrm{RH} 77 \pm 2,5 \%\right)$ in September 1997, using the inoculation method previously described. Evaluations of disease incidence and severity were made four, seven, ten, thirteen and 16 days after inoculation. The resistance reaction was also evaluated through incubation and latency periods. Twenty-eight days after inoculation the existence of latent infection in the resistant progenies was evaluated through vascular discoloration and pathogen isolation from processing material. Disease incidence was observed in $95 \%$ of the progenies. Eight progenies were ranked as moderately resistant and eight as resistant. The average incubation and latency periods were short (4.5 at 4.8 days) for control susceptible progenies and long (11.6 at 12.9 days) for resistant progenies. Latent infection was detected in $45 \%$ of resistant progenies.
\end{abstract}

Keywords: Lycopersicon esculentum, Ralstonia solanacearum, Pseudomonas solanacearum, genetic resistance, inoculation, controlled conditions, incidence, severity, disease progress curve, breeding.

\section{(Aceito para publicação em 09 de novembro de 1998)}

\begin{abstract}
A murcha-bacteriana, causada por Ralstonia solanacearum (Smith) Yabuuchi et al. (Pseudomonas solanacearum (Smith) Smith), é a mais importante doença bacteriana do tomateiro e do pimentão no Nordeste do Brasil, limitando o cultivo destas solanáceas em muitas áreas do estado de Pernambuco (Mariano \& Michereff, 1994). Entre as medidas mais eficientes de controle, inclui-se a resistência ge-
\end{abstract}

nética. Entretanto, o controle efetivo da doença é dificultado pela grande variabilidade fisiológica de $R$. solanacearum, pela extensa gama de hospedeiros do patógeno e pela complexidade que envolve a sobrevivência da bactéria no solo (Kelman, 1976). Várias estratégias têm sido desenvolvidas, sendo algumas de aplicação limitada, geralmente específicas à espécie e ao local onde foram desenvolvidas (Hayward, 1991).
Em relação à cultura do tomateiro, o melhoramento visando incorporação de resistência genética às cultivares tem sido a medida que vem apresentando resultados mais satisfatórios, sendo considerado um dos componentes mais importantes dentro do manejo integrado dessa doença (Prior et al., 1994). O desenvolvimento de cultivares resistentes é o objetivo dos programas de melhoramento (Hayward, 1991; Hartman \& 
Elphinstone, 1994). Embora muitas cultivares resistentes tenham sido desenvolvidas, a resistência frequentemente tem sido quebrada em diferentes regiões de cultivo. Isto acontece, provavelmente, devido à ocorrência de diferentes raças e biovares do patógeno e/ou à inadequação da resistência sob condições ambientais favoráveis ao patógeno (Hayward, 1991; Prior et al., 1994). Por estas razões, a identificação de fontes de resistência à murcha-bacteriana deve ser efetuada utilizando-se isolados do patógeno presentes nas regiões onde a doença é fator limitante, levando-se em consideração as condições ambientais, especialmente a temperatura e a umidade (Gallegly \& Walker, 1949). Na região Norte do Brasil têm sido relatadas algumas cultivares de tomateiro com níveis de tolerância à murchabacteriana. Cheng \& Silva (1988), indicaram a cultivar C-28 N para cultivo no trópico úmido brasileiro por apresentar maior tolerância à murcha-bacteriana $\mathrm{e}$ maior tamanho dos frutos.

Para o melhoramento da cultivar IPA-6, através da incorporação de resistência genética a $R$. solanacearum, foi utilizada a cultivar CL5915-93 por apresentar melhor adaptação às condições de Pernambuco, bem como por ser um material mais precoce e produtivo e com fonte de resistência moderada ao patógeno, em relação às cultivares Hawaii e CRA.

O objetivo deste trabalho foi identificar progênies de tomateiro resistentes a $R$. solanacearum, visando a utilização desses materiais no programa de melhoramento da Empresa Pernambucana de Pesquisa Agropecuária - IPA, para obtenção de uma nova cultivar.

\section{MATERIAL E MÉTODOS}

\section{Seleção em campo.}

O material avaliado foi constituído de uma população de tomateiro na geração $\mathrm{F}_{6}$, obtida pelo cruzamento das cultivares CL5915-93 e IPA-6, avançada pelo método de seleção massal e selecionada para resistência a $R$. solanacearum. As sementes foram produzidas na Estação Experimental do IPA em Belém do São Francisco (PE). As cultivares CL5915-93 (originária do
Asian Vegetable Research and Development Center - AVRDC, em Tainan, Taiwan) e IPA-6 (originária da Empresa Pernambucana de Pesquisa Agropecuária - IPA, em Pernambuco) foram relatadas anteriormente como moderadamente resistente e suscetível, respectivamente, a $R$. solanacearum $\mathrm{em}$ Pernambuco (Silva et al., 1993).

A semeadura foi realizada em bandejas de poliestireno, tipo plantágil, contendo substrato Plantcel (substrato organo-vegetal com macro e micro nutrientes necessários à produção de mudas de hortaliças - Plantágil Indústria e Comércio Ltda, São Paulo - SP), e mantidas em condições de casa-de-vegetação à temperatura média de $35^{\circ} \mathrm{C}$. Utilizou-se o isolado ST de $R$. solanacearum, pertencente à biovar III, proveniente do município de Serra Talhada, Sertão de Pernambuco. O isolado, preservado em água, foi cultivado em meio TZC (Kelman, 1954) para seleção de colônias virulentas. O inóculo foi preparado a partir de cultura com 36 - 48 horas de idade em meio NYDA (Pusey \& Wilson, 1984) e ajustado para a concentração de $5 \times 10^{8} \mathrm{UFC} / \mathrm{ml} \mathrm{em}$ fotocolorímetro a $580 \mathrm{~nm}$, de acordo com curva de crescimento previamente estabelecida. Vinte dias após a semeadura as plantas foram inoculadas, colocando-se sobre o substrato, na base de cada planta, $5 \mathrm{ml}$ da suspensão bacteriana (modificado de Somodi et al., 1993) e transplantadas após duas horas para canteiros de alvenaria no campo $(11,0 \times 1,0 \mathrm{~m})$. Utilizou-se o espaçamento de $30 \mathrm{~cm}$ entre plantas e $50 \mathrm{~cm}$ entre linhas. As plantas testadas compreenderam uma amostra de 660 plantas da população (IPA-6 x CL591593), 90 plantas da cultivar IPA-6 e 30 plantas da cultivar CL5915-93. Foram realizadas avaliações em intervalos semanais até os 70 dias, registrando-se a incidência da doença, através da porcentagem de plantas murchas.

No final do ciclo da cultura, os frutos de cada planta sobrevivente foram coletados e as sementes extraídas. Apenas uma das progênies obtidas, a qual apresentou as melhores características agronômicas desejáveis ao tomateiro para indústria, tais como tamanho, formato e firmeza de frutos, precocidade, produtividade e resistência a meloidoginoses, foi selecionada para retrocruzamento com a cultivar IPA-6.

$\mathrm{O}$ experimento foi conduzido em março de 1996, no Campus da Universidade Federal Rural de Pernambuco (UFRPE), em Recife (PE), com temperatura média de $28 \pm 4^{\circ} \mathrm{C}$ e umidade relativa do ar de $70 \pm 5,5 \%$.

\section{Seleção em casa-de-vegetação.}

Foram avaliadas para resistência à biovar III de $R$. solanacearum em casade-vegetação, 40 progênies de tomateiro, na geração $\mathrm{F}_{2}$, obtidas do retrocruzamento entre uma progênie do cruzamento IPA-6 x CL5915-93 selecionadas no campo e a cultivar IPA-6. Foi realizado um ciclo de seleção, com seleção entre progênies. A metodologia de inoculação foi a mesma descrita anteriormente, sendo as plantas transplantadas para vasos de $5 \mathrm{~kg}$, contendo solo esterilizado, e avaliadas quanto a incidência e severidade da doença. As cultivares IPA-6 e CL5915-93 foram utilizadas como testemunhas suscetível e resistente, respectivamente. A incidência da doença foi verificada aos quatro, sete, dez, treze e 16 dias após a inoculação, e a partir dos dados obtidos foram confeccionadas as curvas de progresso da doença.

Dezesseis dias após a inoculação a severidade da murcha-bacteriana foi avaliada, utilizando-se a escala de notas de Nielsen \& Haynes (1960) com variação de 1 a 5 , onde: 1 = planta sadia; 2 = planta com $1 / 3$ das folhas murchas; 3 = planta com $2 / 3$ das folhas murchas; 4 = planta totalmente murcha e $5=$ planta morta. As leituras da escala de notas foram transformadas em índice de murcha-bacteriana - IMB (Empig et al., 1962) pela seguinte fórmula: IMB $=(\mathrm{CxP}) / \mathrm{N}$, onde $\mathrm{C}=$ nota atribuída em cada classe de sintoma; $\mathrm{P}=$ número de plantas em cada classe de sintoma e N $=$ número total de plantas inoculadas. De acordo com este índice, as progênies foram classificadas para reação ao patógeno como resistente $1,0-2,0$; moderadamente resistente $2,1-3,0$; moderadamente suscetível 3,1 - 4,0 e suscetível 4,1 - 5,0 (Morgado et al., 1992).

No estudo do comportamento de resistência das plantas foram determinados os Períodos de Incubação (PI = tem- 
po em dias requeridos para o desenvolvimento de sintomas visíveis) e Latência $\left(\mathrm{PL}_{50}=\right.$ número de dias requeridos para o aparecimento de $50 \%$ das plantas murchas). As leituras foram realizadas de três em três dias, por um período de 16 dias.

O teste em casa-de-vegetação foi conduzido em setembro de 1997, com temperatura de $35 \pm 5,5^{\circ} \mathrm{C}$ e umidade relativa do ar de $77 \pm 2,5 \%$.

$\mathrm{O}$ experimento foi realizado em delineamento inteiramente casualizado com quatro repetições. Cada parcela foi constituída por um vaso com quatro plantas. Os dados obtidos foram submetidos à análise de variância (ANOVA) e médias comparadas pelo teste de ScottKnott, a 5\% de probabilidade.

Com a finalidade de detectar a existência de infecção latente de $R$. solanacearum nas progênies resistentes, 28 dias após a inoculação o caule de todas as plantas foi cortado no sentido longitudinal e observada a presença de escurecimento dos vasos. Procedeu-se também ao isolamento do patógeno em meio TZC.

\section{RESULTADOS E DISCUSSÃO}

\section{Seleção em campo.}

Do total das 660 plantas testadas em campo, $151(22,9 \%)$ plantas não apresentaram sintomas sendo, potencialmente, resistentes a $R$. solanacearum. A cultivar CL5915-93 exibiu 13,6\% de plantas murchas (Figura 1). Este resultado concorda com Silva et al. (1993) que classificaram esta cultivar como moderadamente resistente ao patógeno, sob condições de casa-de-vegetação. Parte das plantas $\mathrm{F}_{6}$ e testemunha suscetível (IPA-6) exibiram sintomas de murchamento sete dias após inoculação, enquanto CL5915-93 só apresentou sintomas após quatorze dias. A incidência da doença aumentou continuadamente em todos os genótipos, até os 28 dias após a inoculação, permanecendo constante até os 70 dias (Figura 1). Dentre as 151 plantas apenas uma foi retrocruzada com a cultivar IPA-6, as demais estão avançando em seus cruzamentos e posteriormente serão avaliadas quanto a resistência a $R$. solanacearum e outros patógenos.

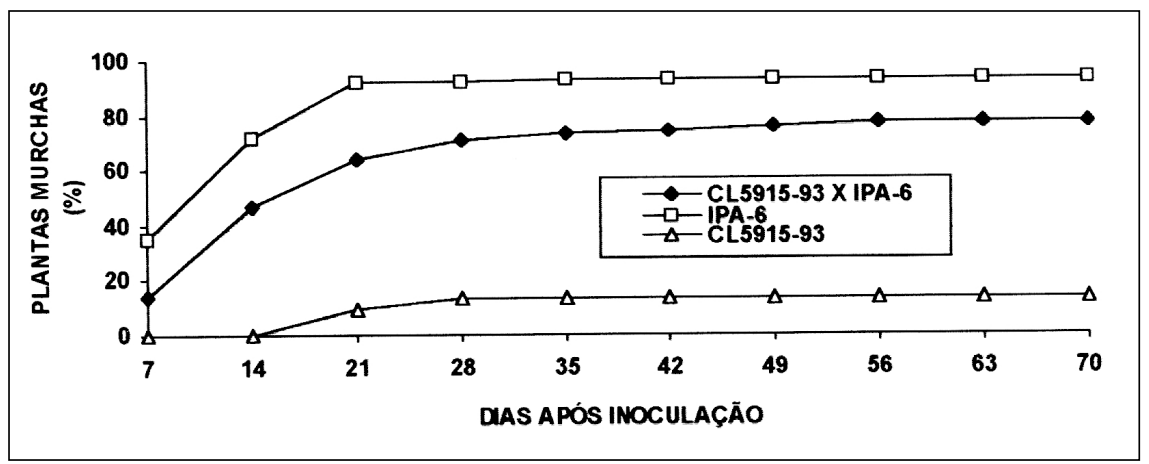

Figura 1. Incidência de murcha-bacteriana em cultivares e em uma população $F_{6}$ (IPA-6 $x$ CL5915-93) de tomateiro, observada em intervalos semanais. Recife, IPA/UFRPE, 1996.

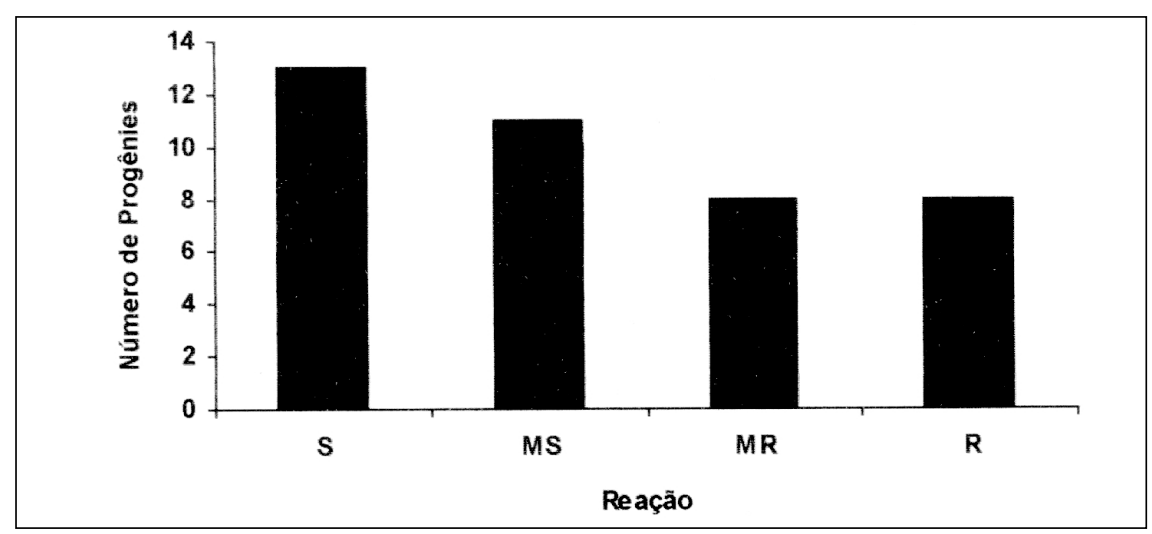

Figura 2. Frequência de reações de progênies de tomateiro à murcha-bacteriana $(\mathrm{S}=$ suscetível, MS = moderadamente suscetível, $\mathrm{MR}=$ moderadamente resistente, $\mathrm{R}=$ Resistente), em condições de casa-de-vegetação. Recife, IPA/UFRPE, 1997.

\section{Seleção em casa-de-vegetação.}

Foi observada incidência de murcha bacteriana em $96 \%$ das progênies testadas. Considerando a classificação proposta por Morgado et al. (1992), do total das 40 progênies, treze foram classificadas como suscetíveis a $R$. solanacearum; onze como moderadamente suscetíveis; oito como moderadamente resistentes e oito como resistentes (Figura 2). Dentre as resistentes (Tabela 1), os menores IMB foram apresentados pelas progênies $\mathrm{P}-3(1,0), \mathrm{P}-4$ $(1,0), \mathrm{P}-12(1,2)$ e P-33 $(1,6)$, que não diferiram significativamente da cultivar CL5915-93 (1,5). As progênies P-21 $(2,0)$, P-34 $(1,9)$, P-38 $(1,8)$ e P-50 $(1,9)$ também foram classificadas como resistentes. Os resultados confirmaram ainda a elevada suscetibilidade da cultivar IPA-6 $(4,8)$.

Comparando-se a curva de progresso da doença entre as progênies resistentes e os seus progenitores, observase que todos os materiais atingiram a incidência máxima dez dias após a inoculação (Figura 3). Sintomas foram observados a partir do quarto dia após a inoculação em $68,8 \%$ das plantas da cultivar IPA-6 e em algumas progênies, variando de 6,2 a 18,8\%. Gomes et al. (1998), ao selecionarem progênies de tomateiro resistentes à murchabacteriana, verificaram que o mesmo isolado ST de $R$. solanacearum também proporcionou elevada incidência de doença, embora diferindo em relação ao período de incubação, que naquele trabalho foi de sete dias. O rápido aparecimento dos sintomas e evolução do progresso da doença nos materiais suscetíveis e moderadamente suscetíveis, pode ter sido provocado pela elevada temperatura $\left(35^{\circ} \mathrm{C}\right)$ detectada no período do ensaio. Em geral, altas temperaturas (28 $-36^{\circ} \mathrm{C}$ ) e alta umidade do solo favorecem o rápido desenvolvimento da doença em tomateiros (Krausz \& Thurston, 1975; Sinha, 1986). Com relação ao comportamento de resistência das plantas, as progênies resistentes foram cla- 
ramente diferentes da testemunha suscetível em relação aos períodos de incubação e latência (Tabela 1). Os PIs e $\mathrm{PL}_{50} \mathrm{~s}$ médios observados foram curtos (4,5 e 4,8 dias) para a testemunha suscetível e longos (11,6 e 12,9 dias), para as resistentes. Verificou-se diferença significativa entre a testemunha resistente e as progênies P-21, P-33, P-34 e P-50 em relação ao PI, sem no entanto diferirem com relação ao $\mathrm{PL}_{50}$. Noda et al. (1986) avaliando a resistência de progênies de tomateiro a $R$. solanacearum sob condições de cultivo em solo naturalmente infestado, verificaram que a murcha-bacteriana apresentou características epidemiológicas bem definidas, na qual níveis elevados de resistência conferidos por um genótipo foram devidos aos baixos níveis de velocidade de progresso da doença na população de hospedeiro.

Foi observado escurecimento dos vasos do xilema em $45,5 \%$ das progênies resistentes, na grande maioria restringindo-se ao sistema radicular e região cotiledonar, que não apresentavam sintomas aparentes de murcha. $\mathrm{O}$ isolamento em meio TZC confirmou a presença de $R$. solanacearum. Na cultivar CL5915-93 foi detectada infecção latente em $35,7 \%$ das plantas. De acordo com Prior et al. (1994), a seleção de genótipos com bons níveis de resistência à murcha-bacteriana deve passar primariamente por uma seleção baseada na incidência e, em seguida, uma avaliação da infecção latente em plantas que não tiverem apresentado sintomas. Apesar de Grimault et al. (1993) relatarem que a invasão do sistema radicular e do coleto era comum e não se encontrava relacionada à suscetibilidade em tomateiros resistentes, segundo QuezadoSoares \& Lopes (1994), a infecção latente pode ser representativa se a produção de mudas for destinada a outras localidades, pois seria uma importante forma de disseminação da doença.

$\mathrm{O}$ método de inoculação utilizado, mesmo sem ferimento das raízes, foi considerado adequado, apesar da alta percentagem de plantas murchas na maioria das progênies, uma vez que confirmou o padrão de resistência da cultivar CL5915-93. De acordo com Hayward (1996), métodos de inoculação

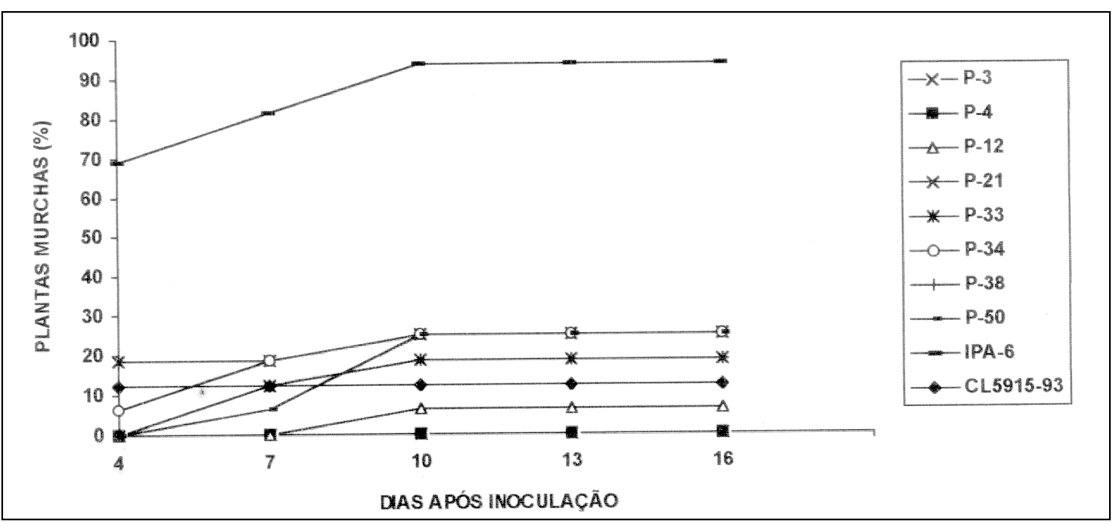

Figura 3. Progresso da murcha-bacteriana em cultivares e progênies resistentes de tomateiro, em condições de casa-de-vegetação. Recife, IPA/UFRPE, 1997.

Tabela 1. Reação de progênies resistentes e cultivares de tomateiro a Ralstonia solanacearum. Recife, IPA/UFRPE, 1997.

\begin{tabular}{cccc}
\hline Genótipo & IMB $^{\mathbf{1}}$ & PI $^{\mathbf{2}}$ (dias) & PL50 $^{\mathbf{3}}$ (dias) \\
\hline P-3 & $1,0 \mathrm{a}^{*}$ & - & - \\
P-4 & $1,0 \mathrm{a}$ & - & - \\
P-12 & $1,2 \mathrm{a}$ & $14,5 \mathrm{a}$ & - \\
P-21 & $2,0 \mathrm{~b}$ & $10,0 \mathrm{~b}$ & $11,5 \mathrm{a}$ \\
P-33 & $1,6 \mathrm{a}$ & $12,2 \mathrm{~b}$ & $13,8 \mathrm{a}$ \\
P-34 & $1,9 \mathrm{~b}$ & $9,2 \mathrm{~b}$ & $13,8 \mathrm{a}$ \\
P-38 & $1,8 \mathrm{~b}$ & $13,0 \mathrm{a}$ & $13,0 \mathrm{a}$ \\
P-50 & $1,9 \mathrm{~b}$ & $10,8 \mathrm{~b}$ & $12,2 \mathrm{a}$ \\
IPA-6 & $4,8 \mathrm{c}$ & $4,8 \mathrm{c}$ & $5,5 \mathrm{~b}$ \\
CL5915-93 & $1,5 \mathrm{a}$ & $13,0 \mathrm{a}$ & $13,0 \mathrm{a}$ \\
\hline CV (\%) & 21,74 & 20,3 & 26,53 \\
\hline
\end{tabular}

*Médias seguidas da mesma letra nas colunas não diferem entre si a $5 \%$ de probabilidade pelo teste de Scott-Knott (5\%)

${ }^{1} \mathrm{IMB}=$ índice de murcha-bacteriana, sendo 1 = planta sadia e 5 = planta morta (Morgado et al., 1992);

${ }^{2} \mathrm{PI}=$ período de incubação do patógeno na planta;

${ }^{3} \mathrm{PL}_{50}=$ período de latência.

mais próximos da realidade de infecção do patógeno demonstram melhor as diferenças entre genótipos suscetíveis e resistentes, embora as possibilidades de escape possam ser maiores.

A seleção de genótipos que possuam resistência à biovar III de $R$. solanacearum poderá ter um importante papel na seleção de tomateiros resistentes à murcha-bacteriana nas condições do Brasil, se a resistência for estável também em condições de temperatura elevada, tendo em vista que a biovar
III predomina nas regiões mais quentes (Lopes et al., 1994). Hanson et al. (1996) também destacam que é fundamental a identificação de genótipos adaptados à região para onde se destinam as futuras cultivares, considerando a variabilidade do patógeno e as condições ambientais predominantes. A identificação de plantas de tomateiro com resistência à murcha-bacteriana, como foi verificado no presente trabalho, é uma das principais estratégias a serem utilizadas no manejo desta doença, ten- 
do como vantagem a compatibilidade com outros métodos de controle, além de não causar efeitos indesejáveis ao agroecossistema e não acarretar aumento dos custos de produção.

As progênies promissoras identificadas neste trabalho serão testadas em áreas com infestação natural de $R$. solanacearum para confirmação da resistência e observação de características agronômicas desejáveis, dando-se preferência às que não apresentarem infecção latente.

\section{AGRADECIMENTOS}

Os autores agradecem à Fundação de Amparo a Ciência e Tecnologia do Estado de Pernambuco (FACEPE) e ao $\mathrm{CNPq}$ pelo financeamento deste projeto de pesquisa.

\section{LITERATURA CITADA}

CHENG, S.S.; SILVA, M.M. C-38 N, nova cultivar de tomate tolerante à murcha bacteriana para trópico úmido brasileiro. Horticultura Brasileira, Brasília, v. 6, n. 1, p. 50, 1988

EMPIG, L.T.; CALUB, A.G.; KATIGBAK, M.M.; DEANON Jr., J.R. Screening tomato, eggplant and pepper varieties and strains for bacterial wilt (Pseudomonas solanacearum) resistance. Philippine Agriculturist, v. 46, p. $303-314,1962$

GALLEGLY, M.E.; WALKER, J.P. Relation of environmental factors to bacterial wilt of tomato. Phytopathology, v. 39, n. 9, p. 932 946, 1949

GOMES, A.M.A.; MARIANO, R.L.R.; MICHEREFF, S.J.; FRANÇA, J.G.E. Selection of Processing Tomato Progenies for Resistance to Ralstonia solanacearum. In: PRIOR, P.; ALLEN, C.; ELPHINSTONE, J. ed. Bacterial Wilt Disease - Molecular and Ecological Aspects. Berlin: Springer-Verlag, 1998. p. 278 - 285.
GRIMAULT, V.; SCHMIT, J.; PRIOR, P. Some characteristics involved in bacterial wilt (Pseudomonas solanacearum) resistance in tomato. In: HARTMAN, G.L.; HAYWARD, A.C. ed. Bacterial wilt. Camberra: ACIAR, 1993. p. 112 - 119. (ACIAR Proceedings 45).

HANSON, P.; WANG, J.F.; LICARDO, O.; HANUDIN; MAY, S.J.; HARTMAN, G.L.; LIN, Y.C.; CHEN, J. Variable reaction of tomato lines to bacterial wilt evaluated at several locations in Southeast Asia HortScience, v. 31, n. 1, p. 143 - 146, 1996.

HAYWARD, A.C. Biology and epidemiology of bacterial wilt caused by Pseudomonas solanacearum. Annual Review of Phytopathology, v. 29, p. 65 - 87, 1991

HAYWARD, A.C. Training course on bacterial wilt caused by Pseudomonas (Ralstonia) solanacearum. Recife: UFRPE, 1996, 34 p.

HARTMAN, G.L.; ELPHINSTONE, J.G Advances in control of Pseudomonas solanacearum race 1 in major food crops. In: HAYWARD, A.C.; HARTMAN, G.L. ed. Bacterial Wilt: the disease and its causative agent, Pseudomonas solanacearum. Wallingford: $\mathrm{CAB}$ International, 1994. p. 157 - 177.

KELMAN, A. Mission of the conference. In: SEQUEIRA, L.; KELMAN, A. ed. Proceedings of the first international planning conference and workshop on the ecology and control of bacterial wilt caused by Pseudomonas solanacearum. Raleigh: North Carolina State University, 1976. p. 1 - 5.

KELMAN, A. The relationship of pathogenicity of Pseudomonas solanacearum to colony appearance on a tetrazolium medium. Phytopathology, v. 44, n. 12, p. 693 - 695, 1954.

KRAUSZ, J.P.; THURSTON, H.D. Breakdown of resistance to Pseudomonas solanacearum in tomato. Phytopathology, v. 65, n. 11, p. 1272 - 1274, 1975

LOPES, C.A.; QUEZADO-SOARES, A.M.; MELO, P.E. de. Differential resistance of tomato cultigens to biovars I and III of Pseudomonas solanacearum. Plant Disease, v. 78, n. 11, p. 1091 - 1094, 1994.

MARIANO, R.L.R.; MICHEREFF, S.J. Lista comentada de bactérias fitopatogênicas registradas e/ou estudadas no Estado de Pernambuco - Brasil. Fitopatologia Brasileira, Brasília, v. 19, n. 4, p. 499 - 508, 1994
MORGADO, H.S.; LOPES, C.A.; TAKATSU, A. Avaliação de genótipos de berinjela para resistência a murcha-bacteriana. Horticultura Brasileira, Brasília, v. 10, n. 2, p. 77 - 79, 1992

NIELSEN, L.W.; HAYNES, F.L. Resistance in Solanum tuberosum to Pseudomonas solanacearum. American Potato Journal, v. 37, p. 260 - 267, 1960.

NODA, H.; VON-DER PAHLEN, A.; SILVA FILHO, D.F. Avaliação da resistência de progênies de tomate à murcha-bacteriana em solo naturalmente infestado por Pseudomonas solanacearum ((Smith) Dows.). Revista Brasileira de Genética, São Paulo, v. IX, n. 1, p. 55 - 66, 1986.

PRIOR, P.; GRIMAULT, V.; SCHMIT, J. Resistance to bacterial wilt (Pseudomonas solanacearum) in tomato: present status and future prospects. In: HAYWARD, A.C.; HARTMAN, G.L. ed. Bacterial Wilt: the disease and its causative agent, Pseudomonas solanacearum. CAB International: Wallingford, 1994, p. 209 - 223.

PUSEY, P.L.; WILSON, C.L. Postharvest biological control of stone fruit brown rot by Bacillus subtilis. Plant Disease, v. 68, n. 9, p. 753 - 756, 1984

QUEZADO-SOARES, A.M.; LOPES, C.A. Resistência de genótipos de tomateiro a biovares I e III de Pseudomonas solanacearum. Horticultura Brasileira, Brasília, v. 12, n. 2, p. 161 - 165, 1994.

SILVA, F.A.G.; MATOS, J.A.R.; MARIANO, R.L.R.; FRANÇA, J.G.E. Resistência de cultivares de tomateiro a Pseudomonas solanacearum. Fitopatologia Brasileira, Brasília, v. 18, p. 293, 1993. Suplemento.

SINHA, S.K. Bacterial wilt in India. In: PERSLEY, G.L. ed. Bacterial wilt disease in Asia and South Pacific. Camberra: ACIAR, 1986. p. 28 - 29.

SOMODI, G.C.; JONES, J.B.; SCOTT, J.W. Comparison of inoculation techniques for screening tomato genotypes for bacterial wilt resistance. In: HARTMAN, G.L.; HAYWARD, A.C. ed. Bacterial wilt. Camberra: ACIAR, 1993. p. 120 - 123. (ACIAR Proceedings 45). 